\title{
Precision quantum devices of generation, modulation and detection of the laser radiation
}

\author{
Pavel Neyezhmakov ${ }^{1, a}$, Mikola Kravchenko ${ }^{1}$ \\ ${ }^{1}$ National Scientific Centre "Institute of Metrology", Mironosytska Str. 42, 61002 Kharkiv, Ukraine.
}

\begin{abstract}
Résumé. Contrairement aux dispositifs quantiques classiques ont été créés lasers hélium-néon avec une excitation à courant continu, un modulateur électro-optique avec une modulation de micro-ondes et des photodétecteurs hétérodynage avec micro-ondes. Ce faible niveau de bruit et les dispositifs quantiques exactes été mis en œuvre une méthode de atogeneratorny auto dans la gamme des micro-ondes. Éléments de la génération, de la modulation et de détection laser construite dans la région avec les plus hauts composants de champ électrique de la gamme des microondes des oscillateurs à résonateur homogènes.
\end{abstract}

\section{The devices of generation}

The processes of excitation in self-excited lasers, oscillators and photoreceivers are considered here.

According to the results of theoretical studies of the resonant excitation of the laser active elements (Figures 1, 2) with helium-neon mixture, the experimental researches on neon passes $3 \mathrm{~S}_{2}-2 \mathrm{P}_{1}$ and $3 \mathrm{~S}_{2}-2 \mathrm{P}_{10}$ and helium-neon lasers for the waves lengths of 0.633 and $0.543 \mu \mathrm{m}$ (Figure 3) were carried out.

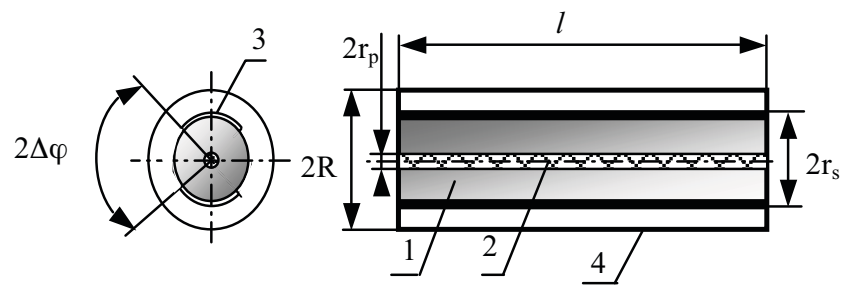

Figure 1. Theoretical model of the helium-neon laser

The laser active element (LAE) is a glass tube 1, inside which there is a capillary tube -2 , and on the external surface of the tube there are two metal bands -3 forming the section of the band line. The high-frequency excited by the band line generates plasma that is the LAE active environment. All the elements mentioned above are installed into the metal tube -4 forming the laser casing to which sides the mirrors forming the optical resonator are connected. As a result, in the considered problem the laser is a cylinder resonator loaded by the band line, dielectric and plasma.

To solve the problem we should suppose the permittivity to be complex, i.e. $\varepsilon=\varepsilon+i \bar{\varepsilon}$, and metal part to be ideally complex. The system ends are metal.

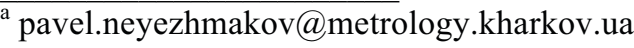

Using Maxwell's equation, we should add the border requirements for the electric $\mathrm{E}$ and magnetic $\mathrm{H}$ fields to them.

The tangential components $\mathrm{E}$ and $\mathrm{H}$ on metal surfaces are equal to zero, and of the borders of dielectric mediums they are continuous. The problem is solved in the cylindrical coordinate system which has $\mathrm{z}$ axis coinciding with the system axis, and the plane corresponding to $\varphi=0$ passes through $\mathrm{z}$ axis and the middle of the band line electrodes. We should suppose the time dependence of the electromagnetic fields to be $\approx \mathrm{e}^{\mathrm{i}} \mathrm{i}_{\mathrm{t}}$. The problem is solved by the method of partial areas with the help of Maxwell's equation and the hypotheses.

To build power lines in the structure (Figure 1) the system of common differential equations is used:

$$
\frac{r d \varphi}{E_{\varphi}}=\frac{d z}{E_{z}} \quad \frac{d r}{E_{r}}=\frac{d z}{E_{z}} \quad \frac{d r}{E_{r}}=\frac{r d \varphi}{E_{\varphi}}
$$

The power lines in the cross sectional plane are calculated from the equation

$$
\frac{d r}{d \varphi}=\frac{r E_{r}}{E_{\varphi}} \text { at } \mathrm{z}=0
$$

and are shown in Figure 2 with solid lines.

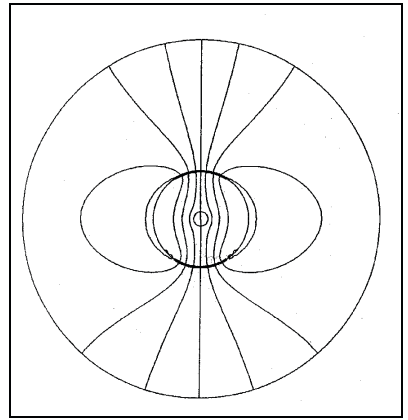

Figure 2. Distribution of power lines 


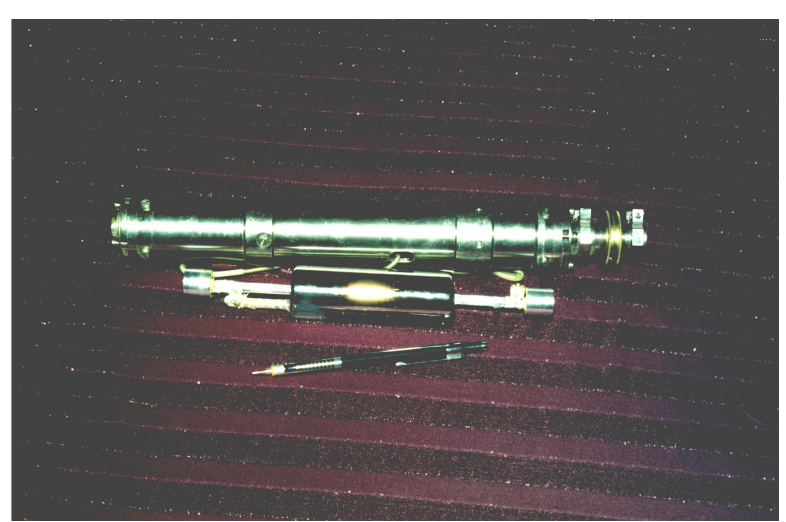

Figure 3. Helium-neon laser of self-excited type, for the wave length of $0.63 \mu \mathrm{m}$ and ratio signal/ noise of $1 \cdot 10^{-4}$

\section{The devices of modulation}

The theoretical studies of processes of electromagnetic oscillations transformation into thermal field in halfaxial microwave resonator (HAMR) and electrooptical crystal KDP (Figures 4, 5) allowed to perform problem-oriented experiments and create precision self-excited modulators with the amplitude modulation coefficient not less than $60 \%$ for the waves lengths of $0.6328 \mu \mathrm{m}$ and $0.4416 \mu \mathrm{m}$.

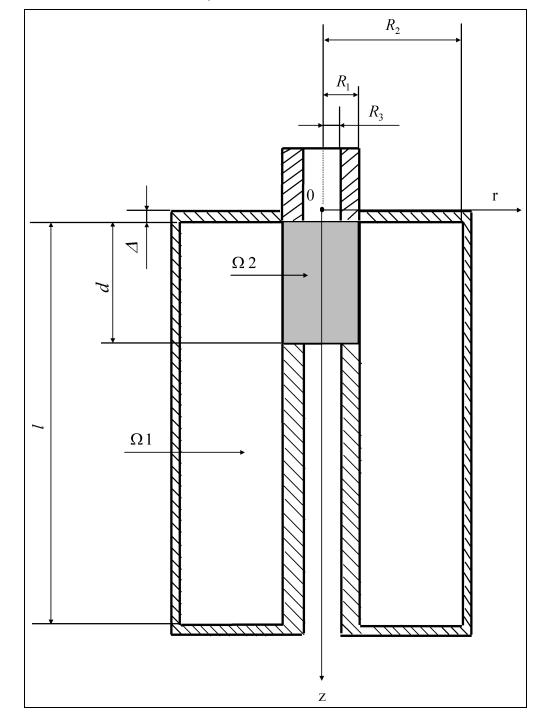

Figure 4. Model of HAMR with the electrooptic crystal KDP $\mathrm{R}_{2}=0.055 \mathrm{~m}, 1=0.15 \mathrm{~m}$

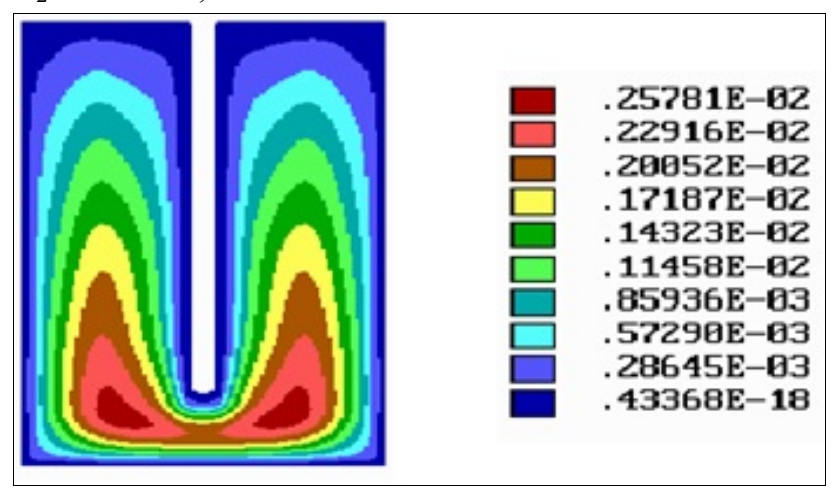

Figure 5. Electromagnetic oscillations in HAMR at $\mathrm{d}=0.022 \mathrm{~m} ; \mathrm{R}_{1}=0.0025 \mathrm{~m}$;

\section{The devices of detection}

The solution of the boundary problems of the Mathematical Physics on the HAMR oscillations loaded both by photoelectronic multipliers and avalanche photodiodes allowed to get the distributions of the electric potential in the HAMR (Figure 6) providing the maximum efficiency of the HAMR and maximum transformation coefficient of the measuring receivers of double-frequency laser radiation.

The algorithm of the problem solution using the photoreceiver consists of several blocks including: construction of the functional correspondence to the boundary problem, the selection of the integration method of the corresponding functional coefficients, the selection of the method of algebraic equations system solution resulting from this functional, the selection of own functions and vectors with the application of Cholesky scheme, determination of the resonant frequency and other resonator characteristics.

After performance of calculations the pictures of distribution and value of the electric potential of the electromagnetic field, the most indicative of which are shown in Figure 6, have been obtained.

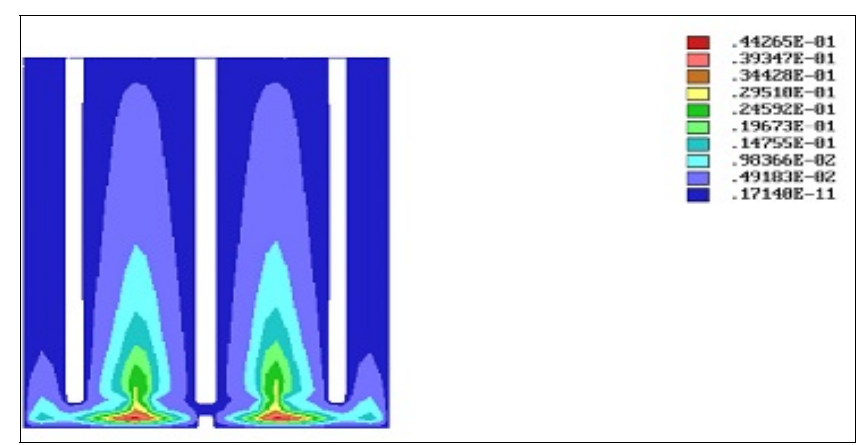

Figure 6. Distribution of the electrical potential of the HAMR electromagnetic oscillations

The performed experiments have confirmed the results of the theoretical researches and allowed to create self-excited measuring photoreceivers (Figure 7) for the waves $0.6328 \mu \mathrm{m}, 0.543 \mu \mathrm{m}$ and 0.4416 $\mu \mathrm{m}$ with complete measurement uncertainty of the phases difference of the laser radiation of not over than \pm 40 ".

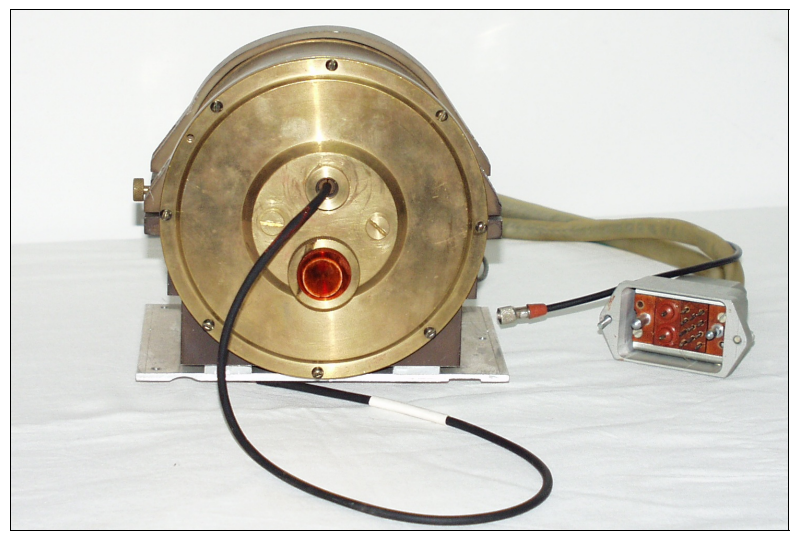

Figure 7. Self-excited measuring photoreceiver for the waves length of $0.6328 \mu \mathrm{m}$ 


\section{Conclusion}

The created low-noise, precision devices of Quantum Electronics have found the application in laser standards of length multiples reproduced in the surface layer of the atmosphere [3].

\section{References}

1. N. I. Kravchenko, P. I. Neyezhmakov, UMJ, 4, 48-57 (2003).

2. N. I. Kravchenko, V. F. Kravchenko, V. L. Rvachev, Reports of the Russian Academy of Science, 321, 1, 6367 (1992).

3. Kravchenko Mykola, Actes Resumes of the $16^{\text {th }}$ International Congres of Metrology, 82, Paris, France (2013). 